\title{
It's a Bird! It's a Plane! It's a Gender Stereotype!: Longitudinal Associations Between Superhero Viewing and Gender Stereotyped Play
}

\author{
Sarah M. Coyne \\ Brigham Young University - Provo \\ Jennifer Ruh Linder \\ Linfield College \\ Eric E. Rasmussen \\ Texas Tech University \\ David A. Nelson \\ Brigham Young University - Provo, david_nelson@byu.edu \\ Follow this and additional works at: https://scholarsarchive.byu.edu/facpub \\ rovin M. Collier

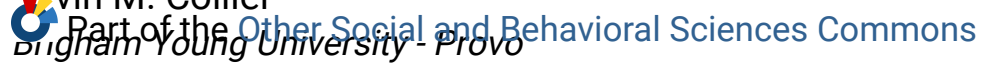

\section{Original Publication Citation}

Coyne, S. M., Ruh Linder, J., *Rasmussen, E. E., Nelson, D. A., \& *Collier, K. M. (2014). It's a bird! It's a plane! It's a gender stereotype!: Longitudinal associations between superhero viewing and gender stereotyped play. Sex Roles, 70, 416-430.

\section{BYU ScholarsArchive Citation}

Coyne, Sarah M.; Linder, Jennifer Ruh; Rasmussen, Eric E.; Nelson, David A.; and Collier, Kevin M., "It's a Bird! It's a Plane! It's a Gender Stereotype!: Longitudinal Associations Between Superhero Viewing and Gender Stereotyped Play" (2014). Faculty Publications. 4558.

https://scholarsarchive.byu.edu/facpub/4558

This Peer-Reviewed Article is brought to you for free and open access by BYU ScholarsArchive. It has been accepted for inclusion in Faculty Publications by an authorized administrator of BYU ScholarsArchive. For more information, please contact ellen_amatangelo@byu.edu. 


\title{
It's a Bird! It's a Plane! It's a Gender Stereotype!: Longitudinal Associations Between Superhero Viewing and Gender Stereotyped Play
}

\author{
Sarah M. Coyne • Jennifer Ruh Linder • \\ Eric E. Rasmussen • David A. Nelson • Kevin M. Collier
}

Published online: 8 May 2014

(C) Springer Science+Business Media New York 2014

\begin{abstract}
Although content analyses have found that superhero programs in the media portray strong gender stereotypes of masculinity, little research has examined the effects of viewing such programs. In the current study, 134 mothers of preschool children (from the Western and Northwestern United States) reported their child's superhero exposure in the media, male-stereotyped play, weapon play, and parental active mediation of the media at two time points (1 year apart). Results revealed that boys viewed superhero programs more frequently than girls, with nearly a quarter of boys viewing superhero programs at least weekly. Analyses revealed that superhero exposure was related to higher levels of malestereotyped play for boys and higher levels of weapon play for both boys and girls from Time 1 to Time 2, even after controlling for initial levels. Parental active mediation did not negate these effects, and even served to strengthen one finding for girls. Specifically, among girls with high superhero exposure, weapon play was highest for girls who received frequent active mediation. Implications of the results are discussed with a focus on whether such programs are developmentally appropriate for preschool children.
\end{abstract}

Keywords Gender stereotypes · Play · Superhero · Media · Weapon $\cdot$ Parental mediation

S. M. Coyne $(\bowtie) \cdot$ D. A. Nelson $\cdot$ K. M. Collier

School of Family Life, Brigham Young University, JFSB 2087,

Provo, UT 84602, USA

e-mail: smcoyne@byu.edu

J. R. Linder

Department of Psychology, Linfield College, McMinnville, OR, USA

\section{E. E. Rasmussen}

College of Media \& Communication, Texas Tech University, Lubbock, TX, USA

\section{Introduction}

Although superheroes in the media are popular among young children in the U.S. (e.g., Brown et al. 2009), research has not examined the influence of viewing superhero programs on gendered forms of play in children. The media tends to portray strong gender stereotypes for both boys and girls. For example, two separate special issues (Rudy et al. 2010,2011) in this journal reveal strong gender stereotypes in multiple mediums including television (Hether and Murphy 2010), movies (Smith et al. 2010) U.S. and International advertisements (Paek et al. 2011), U.S. and Korean magazines (Nam et al. 2011), and music videos (Wallis 2011). Additionally, they call for more research on the effects of viewing gendered behavior in the media (also see Zosuls et al. 2011). Please note that all studies described in this study are based on U.S. samples except where noted.

The aims of the study were fourfold. According to social cognitive theory of gender development (Bussey and Bandura 1999), viewing gender stereotypical behavior in the media can influence play in children. This theory suggests that behavioral outcomes, such as play, are vitally important for both exploring and rehearsing gender roles (Bussey and Bandura 1999). Accordingly, the current study will (1) examine the influence of viewing superhero programs on children's gendered behavior, specifically in reference to play. Additionally, given that there are many weapons in superhero media, viewing such media has the potential to influence weapon play in children, which may be a precursor for aggressive behavior in children (Wegener-Spohring 1994). Accordingly, the study adds to the literature by being the first study, to our knowledge, (2) to examine the effect of any type of media on weapon play. Additionally, theory (Bussey and Bandura 1999) would suggest that boys may be particularly influenced by viewing strong gender stereotypes in the media given that most superheroes are male, and adults and peers are more 
likely to sanction gendered behavior in boys. Therefore the study will (3) examine how viewing strong male gender stereotypes in superhero programs influences both boys and girls. Finally, the vast majority of studies on media effects on gender stereotypes in children are cross-sectional, with longitudinal designs being very rare (e.g., Zosuls et al. 2011). Such a design will allow us to examine whether media or preexisting gender stereotypes are driving any associations between media and gendered play. Thus, the current study adds to the literature by (4) using a longitudinal design to examine these two competing hypotheses. In sum, the aim of the current study is to examine the longitudinal associations between viewing superhero programs in the media and gendered play (including weapon play) in preschool children.

\section{Superhero Programs}

Superheroes have long been popular in U.S. culture, and their popularity only appears to be growing (Worldwide Grosses 2014). For example, in the past 13 years, superhero movies have increased exponentially. Since the year 2000, the United States has seen 70 live action and 41 animated superhero movies, whereas the previous 50 years produced less than half this total (List of American Superhero Films 2014). Superhero movies can be highly profitable; for example, the recently released The Avengers (Feige and Whedon 2012) earned over 1.5 billion dollars worldwide, in ticket sales alone (Marvel's 2012). Apart from big box office releases, there are a number of television series, many aimed specifically at children, such as Ultimate Spider-Man (Bendis and Dini 2012), Young Justice (Register 2010), and Green Lantern (Register and Timm 2011). Even though such programs are not directly aimed at preschool age children, they are still immensely popular with this age group, especially with boys (Brown et al. 2009), given that classic superheroes are usually more identifiable to boys than girls (Martin 2007). Given the popularity of superheroes in the media, the aim of the current study is to examine how viewing such portrayals in the media influences male-stereotyped play in children.

An examination of superheroes in the media reveals that they portray strong gender stereotypes for males. Superheroes are generally portrayed as strong, assertive, aggressive, fast, powerful, leaders, and as portraying a muscular ideal body type (Baker and Raney 2007; Hoffner 1996; McCreary and Sasse 2000; Murnen et al. 2003; Pecora 1992). A recent content analysis found very few gender differences in regard to gender stereotyping for male and female superheroes, with even the females adhering closely to traditional male stereotypes (aggressive, powerful, intelligent, brave, leaders). The few gender differences found were that female superheroes tended to be portrayed as more emotional and overexcited, while male superheroes were more likely to be portrayed as threatening and to show anger (Baker and Raney 2007). Accordingly, superhero programs may communicate some of the strongest media messages regarding masculinity as portrayed in the media today. Despite this, there has been very little research on the effects of viewing superhero programs, especially at young ages.

\section{Effects of Gender Stereotyping in the Media}

In general, research has shown that many types of media portray gender stereotypes, and media exposure to traditional gender stereotypes is associated with gender stereotypes in children (e.g., Collins 2011; Thompson and Zerbinos 1997). Mayes and Valentine (1979) defined gender-role stereotypes as collections of gender-specific attributes or traditional norms that differentiate typical feminine behavior patterns from typical masculine behavior patterns in society. Indeed, the more television children watch, the more stereotypical they are in terms of gendered personality traits (e.g., Frueh and McGhee 1975), occupations (Beuf 1974), domestic activities (Signorielli and Lears 1992), and the more likely they are to believe that men hold a higher status than women (Halim et al. 2013a). A meta-analysis of 30 studies found that television viewing can develop or reinforce children's attitudes regarding gender stereotypes (Herrett-Skjellum and Allen 1996). In contrast, exposure to non-traditional stereotypes is associated with more flexible stereotypes for gender roles (e.g., Brand 1996; Johnston and Ettema 1982). Preschoolers (study done in U.S. and Canada) are particularly vulnerable to such messages, as their perceptions of gender are beginning to be established at this age (Blakemore 2003; Serbin et al. 1993).

However, much of the research on gender stereotypes in the media has focused on females (e.g., Zosuls et al. 2011). This is no surprise given that females are often sexualized and misrepresented in many aspects of media. However, boys can certainly be influenced by gender stereotypes in the media. For example, a number of studies have found that boys construct their masculinity in part by using certain types of media, including television programs, movies, print media, and hip hop music (e.g., Hust 2006; Javors 2004; Prusank 2007; Halim et al. 2013b). With the concept of masculine traits being healthy and desirable, the superhero genre may be taking advantage of already held views of masculinity in the U.S. and perpetuating those traits to a higher extreme or a super idealistic masculinity (Baker and Raney. 2007; Seem and Clark 2006). By so doing, this type of media becomes more popular and more influential. Recent research has found that there are strong themes of masculinity in superhero programs that appeal directly to young boys and many parents are fine with the messages these programs portray (Baker and Raney 2007; Brown et al. 2009; Hoffner 1996; McCreary and Sasse 2000; Murnen et al. 2003; Pecora 1992). Though research has shown that superhero programs are marketed toward and are viewed by young boys, and contain strong gender stereotypes of masculinity, empirical research has not examined the effect of viewing such programs. 
Accordingly, the current study will specifically examine the influence viewing superhero programs have on preschooler's gender stereotyping in terms of play.

\section{Culture}

The value a country places on masculinity may be expressed through the media. According to Hofstede (2001), feelings about masculinity is a defining aspect of culture, with some cultures adhering to masculinity norms more strongly than others. Research has found that masculinity is both valued and rewarded in U.S. culture, with some Asian (e.g., Japan, China) European (e.g. Hungary, Austria), and South American (e.g., Venezuela, Mexico, Colombia) countries reporting even stronger masculinity norms. Middle Eastern (e.g., Egypt, Iraq, Kuwait) countries highly value masculinity as well, though are slightly lower than the U.S. In Hofstede's (2001) research, Norwegian countries (e.g., Sweden, Norway, Finland) were some of the lowest in terms of their value of masculinity norms. Little to no change has occurred in the last 50 years in regards to what the general U.S. public considers as masculine behavior, but traditional feminine behavior has become fluid enough to include both feminine and masculine characteristics as acceptable (Seem and Clark 2006). Masculinity values in the U.S. are shown in part by the media's focus on the production of superhero films, which arguably uphold extremely strong messages regarding masculinity. Though superhero media are generally marketed in the U.S., many different countries outside the U.S. view such programs. For example, the recently released Iron Man 3 (Feige and Black 2013) made twice as much money internationally than domestically (Worldwide Grosses 2014). Though many cultures do not value the strong masculinity norms we see in the U.S. (Hofstede 2001), exposure to superhero programs has the potential to influence acceptance of such norms in other cultures.

\section{Social Cognitive Theory of Gender Development}

Social cognitive theory of gender development provides a useful mechanism to understand why viewing gender stereotyping in the media, particularly in superhero programs, may be associated with greater subscription to male-stereotyped play (Bussey and Bandura 1999). According to this theory, gender development is a complex process that is shaped by three major sources of influence. First, is modeling, where children learn gendered behavior by observing others. The mass media falls under the realm of modeling, as children are exposed to many examples of gender stereotyped behavior in the media. According to the theory, children are more likely to attend to salient, powerful, same-gender models when multiple models are presented. Additionally, they are more likely to learn from models that are rewarded rather than punished for their behavior. Superheroes represent salient and powerful characters that are likely to grab children's attention. An examination of superhero programs reveal that superheroes are most certainly rewarded (e.g., fame, saving the city) for being assertive, aggressive, powerful, strong, and muscular. Accordingly, these models may be very powerful and attractive role models for young children (Baker and Raney 2007). Boys may be particularly influenced by gender messages in superhero programs, as conformity to gender stereotypes tends to be more pronounced and valued for boys than for girls (Bussey and Bandura 1984, 1992; Slaby and Frey 1975). Thus, we would expect the strong themes of masculinity as portrayed in superhero programs to influence preschoolers' activities and play, particularly for boys. Though superheroes clearly live in a fantasy world, preschoolers have not yet developed the ability to distinguish between fantasy and reality, increasing the likelihood that they may be influenced even by fantastical media characters (Davies 1997; Hawkins 1977; Valkenburg 2004).

The second influence is enactive experience, where children learn from the outcomes of their behavior. Accordingly to the theory, children can learn from viewing other-gender models, however, this learning does not always translate into behavior. Most gender-linked behavior is heavily socially sanctioned so children learn quickly that other-gender behavior may be punished by peers or parents. Research has found that this is particularly true for boys; both parents and peers are significantly less tolerant of other-gender behavior for boys as compared to girls (e.g. Sandnabba and Ahlberg 1999). Superhero programs are highly masculinized; accordingly, it is likely that when boys incorporate such messages into their play, peers and adults would socially sanction this behavior. Female superheroes are less common; however, they represent strong, powerful, characters that do not conform to female stereotypes. Though research suggests that girls may learn from viewing such portrayals (e.g., Ashby and Wittmaier 1978; O'Bryant and Corder-Bolz 1978), this learning may not reliably transfer to their play, given that they may experience a swift, negative response from both peers and adults. Again, this part of the theory suggests that superheroes would be more influential for boys than girls.

The third source of influence is direct tuition, where parents verbally instruct children regarding appropriate gender behavior. In the current study, we examine parental mediation, which may be viewed as a type of direct tuition from parents where they can verbally express their feelings regarding the behavior of media characters. Though parents do verbally discuss gender with their children, research shows that this last influence is generally the weakest (Rosenthal and Zimmerman 1978). Accordingly, if we do see any effects of parental mediation, we would expect them to be weak at best.

\section{Play and Gender Role Development}

Important to the current study, social cognitive theory of gender development specifically highlights the importance of examining play in gender role development. First, the theory suggests 
that children's play is "structured and channeled by social influences", including the media (Bussey and Bandura 1999, p. 695). Second, through play, children reinforce learned behavior through the media. Play represents what social cognitive theory calls a "symbolic representation" which is then repeatedly rehearsed, cementing learning of gendered behavior in memory (p. 695). Additionally, play gives children a chance to "practice" the gendered behavior they see in the media that leads to higher levels of self efficacy for behaving in gender stereotyped ways in the future (p. 695).

A focus on play is critical to understanding the development of children in preschool. In the early years of childhood, pretend play, in particular, is rapidly evolving in elaboration and complexity. Child development theorists such as Piaget have long tied great importance to the role of pretend play in early development (Piaget 1932). It is in this context that children may come to act out social roles, with insights gained from observation and emulation of admired adult figures. More importantly, joint pretend play with others, referred to as sociodramatic play, allows for the child to play with and elaborate upon the social symbols they have gained in other contexts, including media exposure.

Generally speaking, pretend play is associated with adaptive functioning (e.g., self-regulation) and, in turn, better social behavior (Elias and Berk 2002; Russ 2004). Both aggressive behavior and pretend play peak during the early childhood years (Peterson and Flanders 2005). Interactions among boys, particularly in the context of sociodramatic play, may include rough and tumble play with an assortment of pretend aggressive behaviors (Fehr and Russ 2013). The availability of toy weapons may also encourage pretend engagement in aggressive pretend play. Significant controversy exists over whether aggression in pretend play should be of concern, with some suggesting that sociodramatic play may reinforce the lessons learned from violent media exposure (Fehr and Russ 2013). This is of particular concern for young boys, who tend to focus on physical aggression in their peer interactions, consistent with the main focus of superhero media. In this study, we aim to assess whether superhero media predicts the amount of gender stereotyped (masculine) play or weapon play in which preschoolers engage.

\section{Weapon Play}

One further aspect of gender stereotyping examined in the current study is playing with toy weapons, a behavior that is more common among boys (Caufield 2002; Smith 1994; Watson and Peng 1992; Wegener-Spohring 1994; Halim et al. 2013b). Indeed, playing with toy weapons is often included in gender stereotype measures for preschool age children (e.g., Golombok and Rust 1993). Though such play is normative among young U.S. and European children, many parents and teachers have concerns that it might lead to aggressive behavior and that weapon play should be discouraged at schools (Costabile et al. 1992; Holland 2003; Smith 1994). Recent school shootings, such as the one in Newtown, CT, tend to exacerbate fears over playing with toy weapons, resulting in policies such as kindergarteners being expelled from school for bringing toy guns to class (Walsh 2013). Though there is some controversy about the acceptability of weapon play, and specifically regarding war play related to superheroes (see Holland 2003; Popper 2013), research has found that children who do play with toy weapons tend to be more physically aggressive (Watson and Peng 1992). Additionally, a large body of research shows that children who view violence on television (including violence with weapons) tend to be more aggressive both in the short and long term (Anderson et al. 2003). Other research has shown a weapons effect where simply seeing an image of a weapon is associated with aggressive behavior (Anderson et al. 1998). Given that superhero programs do involve a wide range of weapons (e.g., bow and arrows, shields, chains, guns, swords, hammers, lasers, batarangs; Brown et al. 2009), the current study will specifically examine this aspect of gendered play.

Exposure to media violence has been associated with a number of outcomes relevant to gender stereotypes (e.g., aggression) and may be transferred to children's play, in the form of gender stereotypes or weapon play (e.g., Anderson et al. 2003; Brown et al. 2009). Often, playful interactions with peers start out with benign intent, but may turn aggressive if the individual is unable to self-regulate or show appropriate levels of the play (e.g., Peterson and Flanders 2005). Though superhero programs do contain violence (which may be related to gender stereotypes), they contain many other non-violent messages about masculinity, as we have detailed earlier in the introduction. Accordingly, to ensure that we are not simply using superhero exposure as a proxy for media violence, we will control for media violence in all major analyses.

\section{Parental Mediation of Media}

Because certain television content has been shown to have undesirable effects on children, researchers have investigated the effectiveness of different methods to help reduce the effects of media on children. Decades of research demonstrate that parental active mediation, or "conversations that parents have with children about television" (Nathanson 2001, pp. $120)$, is consistently one of the most effective ways to reduce the media's negative effect on children (Austin et al. 2009; Nathanson 2001). Specific to superhero media potrayals, Bauer and Dettore (1997) argue that it is the parent's responsibility, through parental active mediation, to educate their children on the reasoning behind the superhero's actions and to make sure that they facilitate the children's development and understanding of the superhero's actions.

Active mediation has specifically been shown to change children's responses to more typical television portrayals of 
gender stereotypes. For example, Corder-Bolz (1980) showed an episode of All in the Family to 500 elementary-school children in which the father, Frank, did stereotypical female chores, such as cooking, and the wife, Irene, did stereotypical male chores, such as fixing appliances. During the show, some of the children heard messages from the experimenters encouraging the acceptance of non-traditional gender roles. Children who heard the mediation message were more accepting of non-traditional gender roles than children who did not receive the mediation message. In another study, 83 kindergarten through sixth-grade children were shown four clips of a television situation comedy in which three daughters in a middle-class family engaged in gender stereotypical behavior, such as giving each other facials and complaining about bugs, dirt, and broken nails while camping (Nathanson et al. 2002). Younger children (K-2nd grade) in the sample who received an active mediation message that explicitly contradicted the stereotypical behaviors portrayed in the show were significantly more accepting of nontraditional gender roles than younger children who did not receive active mediation. Active mediation was thus associated with younger children's belief that women can participate in stereotypically masculine behaviors. The mediation raised younger children's acceptance of non-traditional gender roles to the level of acceptance held by the older children.

It is important to note that neither of these studies reported an effect of the interaction between active mediation and gender. Other developmental differences, such as age, may indeed affect children's responses to active mediation. For example, Cantor and Wilson (1984) found that active mediation had minimal impact on younger children's (age 3-5) emotional responses to a clip from a scary scene from The Wizard of $\mathrm{Oz}$, but produced strong significant changes among children ages 9-11. Similarly, Wilson and Cantor (1987) found that active mediation tended to reduce fear among older children, but increased the fear of younger children, when they were exposed to the snake pit scene in Raiders of the Lost Ark. In addition, Nathanson (2004) argued that younger children may not respond as well to factual mediation because "asking young children to think about and store this kind of information while viewing a television program may exhaust their cognitive resources, making them unable to benefit from a factual approach" (p. 324), while for older children, factual mediation may backfire since they have more cognitive capacity to devote attention to things such as violence without negative evaluations present to bias the processing.

No evidence exists, however, to suggest that the effect of active mediation should be expected to differ based on the child's gender. It is true that boys and girls have different concepts of aggression - boys are typically more physically aggressive than girls (Archer 2004; Bettencourt and Miller 1996; Eagly and Steffen 1986), and girls are more likely to engage in relational aggression (Côté et al. 2007; Underwood et al. 2009) — but scholars have only argued that these gender differences explain why boys and girls respond differently to media depictions of violence (Nathanson and Cantor 2000), and not to the actual active mediation of these media depictions. Therefore, this study explores whether or not active mediation affects boys and girls differently.

Aims of the Study and Hypotheses

Although research has found that superhero programs contain a high amount of gender stereotypes and send strong messages regarding masculinity (Baker and Raney 2007), no research has examined whether viewing such programs leads to increased male-stereotyped play among preschool children. Accordingly, the current study will model whether viewing superheroes in the media is associated with heightened malestereotyped play and weapon play across time, while controlling for initial levels of male-stereotyped play, weapons play, and TV violence. We will also test an alternative model regarding whether male-stereotyped play and weapon play predict heightened superhero exposure over time. It may be that children who are already highly gender stereotyped (in terms of play) may seek out superhero portrayals in the media in the future. In this case, preexisting gender roles would be motivating media choice. Our hypotheses are as follows:

H1 Based on previous research, and social cognitive theory of gender development we predict that viewing high levels of superhero programs will be positively associated with heightened levels of male-stereotyped play and weapon play over time, rather than the alternative direction. We predict that these results will be apparent even after controlling for initial levels of male-stereotyped play, weapons play, and levels of TV violence.

$\mathrm{H} 2$ We examine gender as a moderator in this regard. Given the broad appeal of superheroes to boys (Brown et al. 2009), and research suggesting that children internalize and imitate characters they feel are similar to them (Anderson et al. 2003), we expect these effects to be stronger for boys than girls. Indeed, social cognitive theory of gender development would suggest that viewing stereotypical male behavior in the media would be more influential on play in boys (Bussey and Bandura 1999). Specifically we expect that superhero exposure will be positively associated with male-stereotyped play (including weapon play) over time for boys but not for girls. Though girls may learn from viewing superheroes in the media, we do not expect to see this learning translate into play for girls, as social sanctions against cross-gender play tend to be strong for preschool children (Lamb et al. 1980). Again, we predict this after controlling for initial levels of male-stereotyped play and exposure to media violence. 
H3 We also examine parental mediation as a moderator of superhero exposure and play. Based on research showing that active parental mediation can influence gender role development in children (Nathanson et al. 2002), we predict that higher levels of parental mediation will be associated with a decrease in the strength of the relationship between superhero exposure and male-stereotyped play (including weapon play). However, given that active parental mediation in preschoolers tends to be weaker than other types of mediation, we expect the effects, if any, to be somewhat weak. We examine gender in this regard, but do not any hypothesize gender differences.

\section{Method}

Participants and Procedures

Participants were parents of 134 children (boys, $n=62$; girls $n=72, M$ age $=4.91$ years, $S D=.62$, age range 3 to 6 years old) attending either a university preschool or local preschool in two different Western states. Parents of children were contacted via email and were asked to participate in a study on children and the media. At Time 1 we had a $73 \%$ overall consent rate from parents. One year later, parents were again contacted via email and were asked to participate in a follow up study. Parents received an email with a link to the study and all questionnaires were completed online. One hundred and five parents fully completed the questionnaire at Time 2 , resulting in a $78 \%$ retention rate from Time 1 (boys, $n=50$; girls $n=55, M$ age $=5.81$ years, $S D=.88$ ).

Questionnaires were all parent report, predominantly (98\%) from the mother ( $M$ age at Time $1=34.03$ years, $S D=4.24$ ). For demographic variables, a series of chi-squares showed that the gender distribution was equal for ethnicity, parental relationship status, parental education, and parental income ( $p>.05$ in all comparisons). Parental work status differed as a function of child gender, with more parents working for boys than girls, $\chi^{2}(1)=6.61, p<.05$. Table 1 shows a breakdown for demographic characteristics.

\section{Measures}

Parents reported on a variety of variables for their children, both at Time 1 and Time 2.

\section{Superhero Exposure}

Parents were shown a number of pictures depicting common superheroes (e.g., Spiderman, Batman, Captain America, $\mathrm{X}$-men) and were asked "How often does your child watch television shows or movies (including DVDs) portraying
Table 1 Demographic characteristics by child gender

\begin{tabular}{lcc}
\hline & \multicolumn{1}{l}{ Boys } & Girls \\
\hline Ethnicity & & \\
$\quad$ White & $43(88 \%)$ & $51(92 \%)$ \\
$\quad$ Other & $6(12 \%)$ & $5(8 \%)$ \\
Parental relationship status & & \\
$\quad$ Married & $43(91 \%)$ & $53(98 \%)$ \\
$\quad$ Other & $4(9 \%)$ & $1(2 \%)$ \\
Parental education & $10(21 \%)$ & $12(22 \%)$ \\
$\quad$ Less than a Bachelor's & $20(48 \%)$ & $28(52 \%)$ \\
Bachelor's degree & $17(36 \%)$ & $14(26 \%)$ \\
Higher degree (e.g. MSc, PhD) & & \\
Work outside the home ${ }^{\mathrm{a}}$ & $21(46 \%)$ & $12(22 \%)$ \\
$\quad$ Yes & $25(54 \%)$ & $42(78 \%)$ \\
No & & \\
Income & $6(14 \%)$ & $4(7 \%)$ \\
$<\$ 30,000$ & $19(43 \%)$ & $24(49 \%)$ \\
$\$ 30,001-\$ 80,000$ & $19(43 \%)$ & $23(46 \%)$ \\
$>\$ 80,0000$ &
\end{tabular}

${ }^{\mathrm{a}}$ Comparison is significant at $p<.05$ level

superheroes (like the ones depicted above?)". Responses for this single-item measure were indicated on a 7-pointLikert scale ( $0=$ "never", $6=$ "2-3 times a week"), and an assessment was made at both time points.

\section{Male-Stereotyped Play}

Parents completed a modified version of the Preschool Activities Inventory (Golombok and Rust 1993), a 14-item measure of gender stereotyping in terms of activities and play of preschoolers. Modified items included changing "fighting" to "play fighting or wrestling" and changing "dressing up in girlish clothes" to "playing dress up". Parents were asked to rate how frequently their child engaged in a number of activities during the past month (e.g., "Playing house (e.g., cleaning, cooking)"', "Sports and ball games") on a 5-point-Likert scale ( 1 = "never" to 5 = "very often"). As is typical with this measure, stereotypically female items were reversed coded, and all items were averaged, so a higher score indicated more male gender stereotyping. Cronbach's alpha was acceptable at both time points (Time 1, $\alpha=.83$; Time 2, $\alpha=.86$ ).

\section{Weapon Play}

Two additional items from the Preschool Activities Inventory (Golombok and Rust 1993) were measured separately to assess the frequency with which toy weapons (guns, swords, or other objects being used as guns or swords) are used during play. For these items, parents were asked to indicate how 
frequently their child played with different toys during the past month, again on a 5-point-Likert scale $(1=$ "never" to $5=$ "very often"). These items were averaged and higher scores indicated higher levels of weapon play. Cronbach's alpha was acceptable at both time points (Time 1, $\alpha=.76$; Time 2, $\alpha=.83$ ).

\section{Television Violence}

Many of the superhero programs have been criticized for portraying high levels of media violence, which can be associated with gender stereotypes, such as aggressive behavior (Brown et al. 2009). Accordingly, to ensure that our findings were not simply a reflection of the programs being violent, we used television violence exposure (assessed at Time 1) as a control measure throughout the study. Parents were asked to indicate their children's three favorite television programs. For each, they were given a detailed definition of physical violence (including examples) and were asked to rate how violent each program was on a 7-point-Likert scale $(1=$ "none at all" to 7 = "very high amount"). Media violence scores across the three favorite programs were averaged and higher scores represented higher levels of media violence exposure on television. Such a technique has been used in a number of media violence studies, with viewer self-reported ratings of media violence being correlated with expert ratings of violence at $r=.75$ (e.g., Anderson et al. 2007; Gentile et al. 2004).

\section{Parental Mediation}

Parents reported their active mediation of their child's media by responding to three items (e.g., "How often do you try to help your child understand what he/she sees in the media?") using a 5-point-Likert scale ( 1 = "never" to 5 = "very often"; Nathanson and Botta 2003). These items were averaged and higher levels indicated higher levels of parental mediation. Cronbach's alpha was acceptable at both time points (Time 1, $\alpha=.88$; Time $2, \alpha=.87$ ).

\section{Results}

Preliminary assumption testing was first conducted to check for normality, linearity, univariate and multivariate outliers, homogeneity of covariance matrices, and multicollinearity (VIF ranged from 1.01 to 1.45). The data met the conditions for each of the above for subsequent analyses, however, weapon play was moderately skewed for girls. We attempted a number of transformations of the data, however, this did not make a substantial difference in the results or the distribution of the data. Accordingly, we use the original data in the analyses below, though we note that this variable be viewed with some caution.
Preliminary Analyses

We first examined gender differences for all main variables. First, we noted that there was a large range of superhero viewing, especially for boys. Twenty percent of boys had never seen any media portraying superheroes, while about $20 \%$ viewed it at least once a week or more. The remainder of the boys viewed such programs occasionally, anywhere from less than once a month to $2-3$ times a month. The range was more restricted for girls, with nearly half never viewing or only viewing superhero programs once, and only $2 \%$ viewing such programs once or more a week.

A Multivariate Analysis of Variance (MANOVA) was conducted using gender as the independent variable and superhero viewing, violence in the media, male-stereotyped play, weapons play, and parental mediation at both time points as the dependent variables. The analysis revealed a significant overall effect for gender, $F(10,73)=23.93, p<.001$; partial $\eta^{2}=.77$. Table 2 shows means and standard deviations for main variables at both time points. Boys were exposed to significantly more superhero programs, time $1: F(1,82)=$ $6.97, p<.01$; partial $\eta^{2}=.08$, time $2: F(1,82)=12.34 p<.010$; partial $\eta^{2}=.13$, and violence in the media, time $1: F(1,82)=$ 9.18, $p<.01$; partial $\eta^{2}=.10$, time $2: F(1,82)=17.42, p<.001$; partial $\eta^{2}=.18$, as compared to girls. Boys also showed significantly higher levels of male-stereotyped play, time 1 : $F(1,82)=206.45, p<.001$; partial $\eta^{2}=.72$, time $2: F(1,82)=$ 161.94, $p<.001$; partial $\eta^{2}=.66$, and weapon play, time 1 : $F(1,82)=34.21, p<.001$; partial $\eta^{2}=.29$, time $2: F(1,82)=$ 31.94, $p<.001$; partial $\eta^{2}=.28$, as compared to girls. There was no gender difference for active parental mediation at either time point, time $1: F(1,82)=.59, p=.45$; partial $\eta^{2}=.01$, time $2: F(1,82)=.39, p=.54$; partial $\eta^{2}=.01$.

Table 2 Estimated marginal means and standard errors for all variables by gender

\begin{tabular}{|c|c|c|c|c|c|}
\hline & \multicolumn{2}{|l|}{ Boys } & \multicolumn{2}{|l|}{ Girls } & \multirow[t]{2}{*}{ Scale range } \\
\hline & M & SE & M & SE & \\
\hline T1: Superhero programs* & 3.71 & .26 & 2.77 & .25 & $0-6$ \\
\hline T2: Superhero programs* & 4.15 & .27 & 2.81 & .27 & $0-6$ \\
\hline T1: TV violence* & 1.80 & .11 & 1.32 & .11 & $1-7$ \\
\hline T2: TV violence* & 2.41 & .15 & 1.57 & .14 & $1-7$ \\
\hline T1: Male-stereotyped play** & 3.52 & .06 & 2.42 & .06 & $1-5$ \\
\hline T2: Male-stereotyped play** & 3.59 & .07 & 2.38 & .07 & $1-5$ \\
\hline T1: Weapon play** & 2.70 & .12 & 1.73 & .11 & $1-5$ \\
\hline T2: Weapon play** & 3.13 & .16 & 1.91 & .15 & $1-5$ \\
\hline T1: Active mediation & 3.10 & .08 & 3.12 & .08 & $1-5$ \\
\hline T2: Active mediation & 3.64 & .11 & 3.73 & .11 & $1-5$ \\
\hline
\end{tabular}

Gender differences as found by the MANOVA are marked: $* p<.01$; ${ }^{* *} p<.001 ; \mathrm{T} 1=$ Time $1 ; \mathrm{T} 2=$ Time 2 
Table 3 Bivariate correlations of main variables

\begin{tabular}{|c|c|c|c|c|c|c|c|c|c|c|}
\hline & 1. & 2. & 3. & 4. & 5. & 6. & 7. & 8. & 9. & 10. \\
\hline 1. Superhero programs (T1) & - & $.63 * * *$ & $.32 *$ & $.40 * *$ & $.40 * *$ & $.44 * *$ & $.45^{* *}$ & .28 & .08 & .06 \\
\hline 2. Superhero programs (T2) & $.72 * * *$ & - & $.29 *$ & $.28 *$ & .18 & $.37 * *$ & $.37 * *$ & $.46^{* * *}$ & -.05 & -.09 \\
\hline 3. Male-stereotyped play (T1) & -.12 & .11 & - & $.64 * * *$ & .16 & .28 & .16 & .04 & -.03 & .03 \\
\hline 4. Male-stereotyped play (T2) & .07 & $.24+$ & $.63 * * *$ & - & $.25+$ & $.46^{* * *}$ & .17 & .08 & .06 & .05 \\
\hline 5. Weapon play (T1) & .12 & .22 & .06 & .13 & - & $.66^{* * *}$ & $.42 * *$ & $.39 * *$ & .22 & .23 \\
\hline 6. Weapon play (T2) & $.32 *$ & $.42 * *$ & .17 & $.32 *$ & $.60 * * *$ & - & $.36^{*}$ & $.41^{* *}$ & .24 & .19 \\
\hline 7. TV violence $(\mathrm{T} 1)$ & .25 & .18 & -.20 & -.01 & .15 & -.02 & - & $.61 * * *$ & .08 & -.02 \\
\hline 8. TV violence $(\mathrm{T} 2)$ & $.40 * *$ & $.50 * * *$ & .03 & .23 & .22 & $.34^{*}$ & $.45 * * *$ & - & -.11 & -.09 \\
\hline 9. Active mediation (T1) & -.13 & .01 & .21 & .06 & -.02 & -.08 & .07 & -.04 & - & $.84 * * *$ \\
\hline 10. Active mediation (T2) & $-.35^{*}$ & -.21 & .23 & .15 & .03 & -.05 & -.01 & -.11 & $.79 * * *$ & - \\
\hline
\end{tabular}

$+p<.10 ; * p<.05 ; * * p<.01 ; * * * p<.001$. Boys represented in the upper diagonal, girls in the lower diagonal. T1 $=$ time $1 ; \mathrm{T} 2=$ time 2

Additionally, at the bivariate level, most study variables were positively correlated with each other as expected (see Table 3 for full correlation matrix as split by gender). For boys, superhero exposure was associated with higher levels of male-stereotyped play and weapon play at every time point, and importantly, over time. For girls, superhero exposure was only associated with weapon play, and only at Time 2 . Additionally, television violence was strongly associated with superhero exposure and weapon play, but for boys only.

\section{Main Analyses}

\section{Male-Stereotyped Play and Weapon Play Over Time}

Hypothesis 1 suggested that superhero media would be associated with heightened male gendered play over time. To examine this possibility, a structural model using the maximum likelihood data estimation method was analyzed with the Analysis of Moments Structure (AMOS) software [version 20]. Participants for this model consisted of individuals with both time 1 and time 2 data $(n=105)$. This model considered exposure to superhero programs at Time 1 predicting malestereotyped and weapon play at Time 2. Male-stereotyped play, weapon play, and TV violence at Time 1 all served as control variables. Hypothesis 2 predicted that effects of superhero media would be stronger for boys than girls. To test for group differences as a function of the gender of the child, a series of multi-group models were estimated and compared using chi-square difference tests. Structural paths were examined by comparing models where paths were free to vary across child gender to a model where paths were constrained to be equal across gender. Comparing the fully constrained model to the fully unconstrained model resulted in a significant decrease in model fit, $X^{2}$ difference $(8)=18.76, p<.05$, suggesting structural variance as a function of child gender. Thus, the best fitting model was a fully unconstrained model, allowing all paths to freely vary across gender.
The final model resulted in adequate fit, $X^{2}(4)=4.86$, $p=.30 ; \mathrm{CFI}=.99$, RMSEA $=.05$; RMSEA $90 \%$ CI .000 .162 . Although male-stereotyped play and weapon play were highly stable over time, viewing superheroes in the media at Time 1 predicted higher levels of male-stereotyped play for boys only, $\beta=.29, p<.05$, and weapon play for both girls, $\beta=.29, p<.05$, and boys, $\beta=.25, p<.05$, at Time 2 , even after controlling for initial levels of these variables at Time 1 (see Fig. 1).

\section{Alternative Model}

We also examined an alternative model, one where malestereotyped play and weapon play predicted higher levels of superhero viewing over time. The model was completely saturated, so model fit statistics are not shown. Exposure to superhero media was highly stable over time. Neither malestereotyped play, $\beta=.10, p>.05$, nor weapon play, $\beta=-12$, $p>.05$, predicted change in the levels of superhero programs over time for boys. Conversely, male-stereotyped play did predict higher levels of superhero programs over time for girls, $\beta=.20, p<.05$, though weapon play did not, $\beta=.04, p>.05$ (See Fig. 2).

\section{Parental Mediation}

Hypothesis three suggested that active parental mediation would moderate associations between superhero exposure and gendered play. Additionally, we examined gender as a potential moderator in these analyses. For parental mediation, because the measures of active mediation are continuous measures, we conducted two hierarchical regression analyses to determine if active mediation altered the effect of superhero exposure on children's male-stereotyped play and weapon play. These analyses also explored whether the effect of active mediation depended on children's gender. Each of the analyses was conducted using Hayes (2013) PROCESS SPSS 
Fig. 1 Structural model of superhero exposure predicting male-stereotyped play and weapon play over time

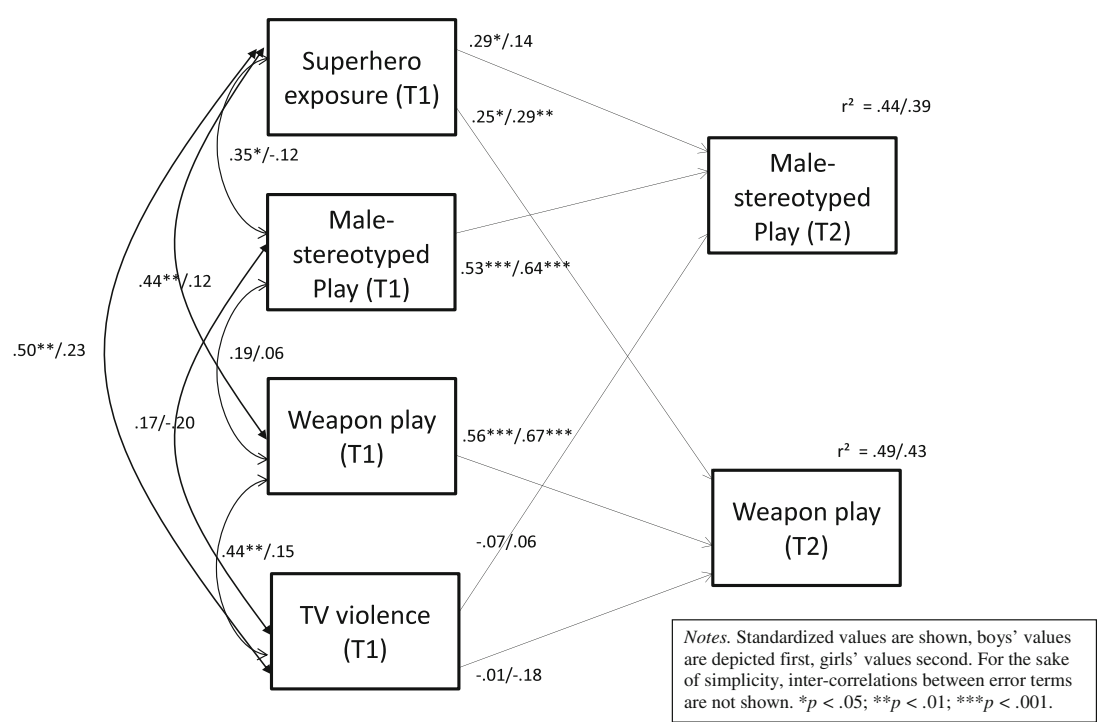

macro computational tool. This tool conducts hierarchical regression analyses, allowing for testing the effect of a moderating variable (the active mediation variable) and for the effect of a three-way interaction (adding gender to the model). The analyses were not included in the SEM model in order to allow for statistical pick-a-point probing of the interactions. The PROCESS tool allows for statistically probing the effect of the primary interaction with alpha set at .05 using the complete multiple regression model and all cases contributing to that model at assigned values of the primary moderator (the active mediation variable) and the secondary moderator (gender). In this way, pick-a-point probing can provide us with an estimate of the effect of the focal predictor at different representative values of the moderators (Hayes and Matthes 2009), giving us a better understanding of the conditions under which the relationship between the superhero exposure and effects of that exposure is significant. For simplicity, we only report the results of the hypothesized interactions below.

For the first regression model, with Time 2 gender stereotyping as the dependent variable, step 1 included Time 1 (T1) active mediation, (T1) superhero exposure, gender, (T1) TV violence exposure, and (T1) male-stereotyped play. Step 2 included the products of (a) (T1) superhero exposure and (T1) active mediation, (b) (T1) superhero exposure and gender, and (c) (T1) active mediation and gender. The final step included the three-way interaction of (T1) superhero exposure, (T1) active mediation and gender. Results revealed that the relationship between superhero exposure and malestereotyped play at Time 2 did not depend on active mediation, $p>.05$. Results of the three-way interaction revealed that
Fig. 2 Alternative model of male-stereotyped play and weapon play predicting superhero exposure over time

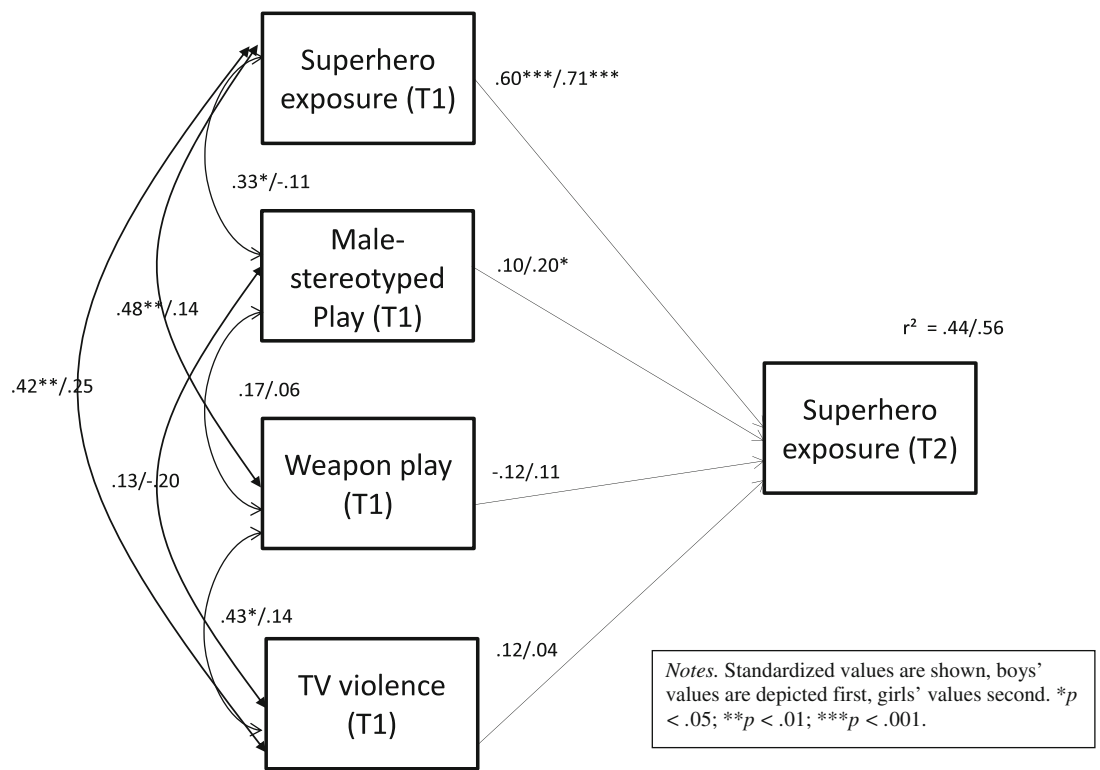


this interaction did not differ based on children's gender, $p>.05$. Probing of the three-way interaction revealed no significant effect at any level of active mediation for either gender.

The second regression model replicated the first regression model, except this model predicted Time 2 weapon play instead of Time 2 male-stereotyped play; accordingly, (T1) male-stereotyped play was also replaced in the model with (T1) weapon play. Results failed to find a significant interaction between active mediation and superhero exposure or a three-way interaction between superhero exposure, active mediation, and gender. However, probing of the three-way interaction revealed a significant effect of active mediation on the relationship between superhero exposure and weapon play for girls at high levels (one standard deviation above the mean) of active mediation by parents, $\beta=.24, p<.05$. Specifically, among girls with high superhero exposure, weapon play was highest for girls who received frequent active mediation. On the other hand, among girls with low superhero exposure, weapon play was lowest for girls who received frequent active mediation. This interaction is shown graphically in Fig. 3.

\section{Discussion}

This study examined longitudinal associations between preschoolers' superhero exposure in the media and subsequent male-stereotyped play and weapon play, and whether active parental mediation moderated these associations. The longitudinal aspect of this study is especially important as it allows some insight into the direction of effects for superhero media on various types of gendered play. In general, preschool boys viewed substantially more television programs and movies portraying superheroes. This confirms a growing body of research that shows that superhero programs appeal to young boys (Brown et al. 2009), likely because of the action/ adventure nature of the programs and the high number of male superhero characters. However, even though boys were much more likely to view superhero programs, there was a wide range in viewing, with many boys never viewing such programs while others view them multiple times each week. Accordingly, it appears that parents themselves have different views of whether viewing superhero programs are appropriate for preschool age children, given that many completely restrict or limit access at this age.

\section{Male-Stereotyped Play}

We found that boys who viewed superhero programs were more gender stereotyped in terms of their play and activities 1 year later, even after controlling for initial levels of gender stereotyped play and other controls. Notably, our alternative model did not find the opposite - that male-stereotyped play led to more superhero exposure over time for boys, suggesting that media may be driving the association between these two variables over time. This confirms existing research demonstrating that exposure to gender stereotypes in the media can
Fig. 3 The moderating effect of active mediation on the relationship between superhero exposure and weapon play for boys and girls

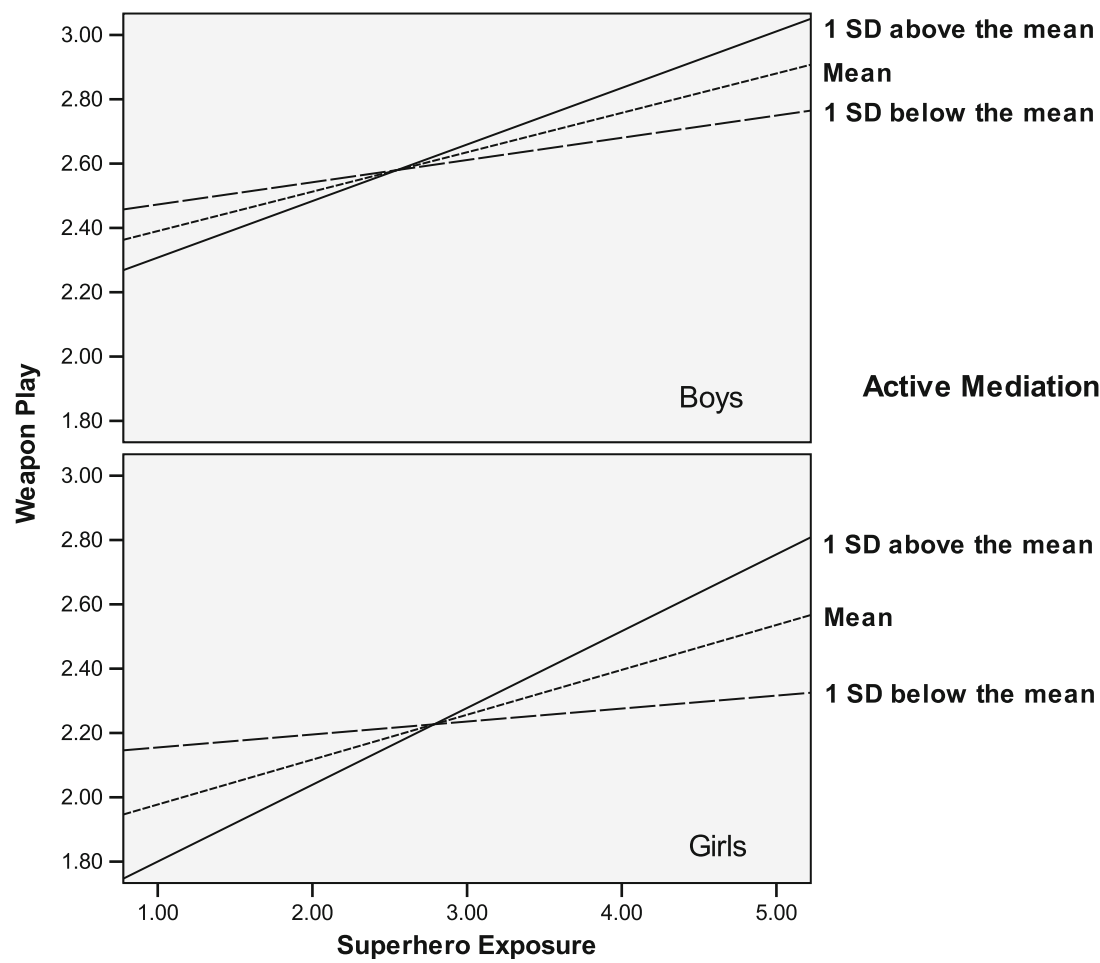


influence behavior in real life (e.g., Herrett-Skjellum and Allen 1996). To our knowledge, this study is the first to specifically examine superhero programs, a media genre that has been criticized for promoting hyper-masculinity among children (Brown et al. 2009). The vast majority of superheroes (including female characters) are portrayed as powerful, strong, aggressive, muscular, and as leaders. Preschool boys who regularly view such programs appear to be internalizing such messages and show heightened gender stereotypes in terms of play and activities a year later. According to social cognitive theory of gender development (Bussey and Bandura 1999) children are most likely to learn from characters that are highly salient, powerful, and rewarded for their behavior. Superheroes are generally portrayed positively and are rewarded, essentially for prescribing to hyper-masculinity norms. Accordingly, boys learn a powerful lesson regarding what it means to be a man from these programs, which is then translated into their own gendered play.

Conversely, we did not find the same effect for girls. Given that girls view less superhero programs and there are fewer female characters, it was not surprising that the effects were stronger for boys. However, when female superheroes are portrayed, they typically portray the same masculine traits as male superheroes (Baker and Raney 2007). Some research would suggest that viewing counter-stereotypes regarding gender may decrease gender stereotyping in children (e.g., Brand 1996; Johnston and Ettema 1982); however, this was not found in our study. Girls who frequently viewed superhero programs exhibited similar levels of male-stereotyped play as those who viewed these programs less frequently. This confirms social cognitive theory of gender development (Bussey and Bandura 1999) which suggests that though girls may learn about gender from viewing opposite gender characters, this may not translate into their actual play, which may be more influenced by peer norms. It may be that preschool girls are also consuming large amounts of media that are reinforcing feminine traits. For example, media that features princesses is very popular among preschool girls (e.g., Iger 2006) and contains highly stereotypical portrayals of gender (England et al. 2011). Perhaps for girls, viewing the masculine behavior of superheroes is not sufficient to counteract their exposure to highly feminine representations in other media. Future research should address this possibility by examining superhero exposure within the context of the complete media diet of young children.

Instead, the results of the current study may shed some light on the relationship between superhero exposure and malestereotyped play for girls. We found that girls who show higher levels of male-stereotyped play at time 1 were more likely to view superhero programs in the media at time 2 . Interestingly, we did not find a concurrent association between viewing superhero programs and male-stereotyped play at time 1. Accordingly, this provides some evidence that levels of gender stereotyped play can shape media choices in the future. As we mentioned earlier, we did not find this for boys. Higher levels of superhero exposure and male-stereotyped play were both quite rare for girls and it may be that we see this direction of results only in regards to counter-stereotypical behavior.

\section{Weapon Play}

Although superhero effects for male-stereotyped play were specific to boys, our results revealed that both boys and girls who viewed superhero programs were more likely to play with toy weapons in the future, even after controlling for initial levels and other controls. Weapon play did not predict higher levels of superhero exposure for either boys or girls, suggesting that media may be driving the association between these two constructs, at least over time. Superheroes certainly use a broad range of weapons throughout the programs, and this appears to filter into the play of children who watch these programs. These results fit well in the context of social cognitive theory of gender development (Bussey and Bandura 1999); if superheroes are rewarded for using weapons, then children are more likely to integrate weapons in their own imaginative play. This confirms some of the earliest media violence research which examined associations between media violence and aggressive play, with children in the classic Bobo doll study being more likely to imitate an aggressive model in their own play (Bandura et al. 1963). However, unlike general play, viewing superheroes in the media did influence weapon play in girls. This went against our hypotheses, but we can speculate why superheroes would influence weapon play but not general play in girls. Weapon play is very rare in girls, especially when they play with other girls (e.g., Caufield 2002). Given that sociodramatic play involving both superheroes and weapons is much more common among boys, it may be that we only see this behavior among girls when they are interacting with boys. If girls are playing with boys then we would not see any of the typical social sanctions against gendered play as suggested by the social cognitive theory of gender development (Bussey and Bandura 1999). It may be that girls who view superhero programs are also more likely to have male playmates than girls who do not view superhero programs. We did not measure the gender of our participants' playmates, though, so future research should examine this possibility directly.

Whether weapon play is problematic in preschool-age children is under scrutiny (Holland 2003; Popper 2013). Although some research suggests that playing with weapons is associated with aggressive behavior in children (Watson and Peng 1992), parents and teachers in a number of cultures hold a wide range of attitudes concerning the acceptability of such play (Costabile et al. 1992). Perhaps more concerning is the potential spillover effect of weapon play on aggressive 
behavior, given that research has found a weapons effect whereby simply viewing a weapon is associated with increased aggressive thoughts and behavior (Anderson et al. 1998). Though we did not examine aggressive behavior in the current study, future research should examine whether viewing superhero programs leads to both increases in weapon play and physical aggression. Though media violence has been associated with aggressive behavior (Anderson et al. 2003), it will be important to examine the long-term consequences of superhero exposure, given the high levels of violence combined with the many non-violent messages related to masculinity and power found in superhero programs.

\section{Parental Mediation}

This study found little evidence that active mediation can influence how young children's gendered behaviors are affected by exposure to superhero programming. Normatively, preschoolers are extremely rigid in their gender stereotypes because they are working on the development of their gender identity (Ruble et al. 2006). Accordingly, preschoolers may be resistant and less responsive to mediation messages regarding gender portrayals in the media. It is also possible that younger kids simply do not respond to active mediation in the way they do to other forms of mediation, such as restrictive mediation. Restrictive mediation entails the setting of rules for children's television exposure, such as limiting how much television children can watch or not allowing them to watch certain programming (Nathanson 2001). Mediation research shows a consistent pattern that younger children respond better to restrictive mediation than older children (Nathanson 2001).

Results also showed that active mediation may actually enhance the effects of children's exposure to superhero programming on weapon play for frequent viewers of superhero programming (at least for girls). For young children, this finding is not entirely unexpected. Bussey and Bandura's (1999) social cognitive theory of gender development suggests that children learn socially through vicarious behavioral exemplars. Therefore, parental mediation that is intended to direct children's attention to specific media messages and character attributes should increase the attention, and thus the cognitive effort and elaboration, that children give to the messages and character attributes. By directing a child's attention to an anti-social message, we should expect greater learning and integration of that message into the children's cognitive representation of that message, which could result in beliefs, attitudes, and behaviors that the parent considers undesirable. Perhaps this explains why young children respond better to restrictive mediation than to active mediation-instead of focusing children's attention on the content of media messages, as active mediation has the potential to do, children are preempted from having the opportunity to pay attention to the message via restrictive mediation.

\section{Limitations of the Study and Conclusions}

Although this study has many strengths, including the longitudinal nature of the data and the focus on preschool children, there were a number of limitations that should be noted. First, although the sample had some geographical diversity in its makeup (both university and local preschools in two different states), the majority of children came from White, middle class families in the United States. Accordingly, future research should replicate these results using a diverse population. Additionally, all questionnaires were parent-report. Parents tend to rely on their own gender stereotypes in their reporting of gender-type behavior in children. Though we have analyzed everything separately by gender to reduce this bias, preliminary gender differences should be viewed with caution. Though all scales showed good reliability, future research should utilize observational or teacher reports as additional methodologies. Furthermore, superhero exposure was rated by a single item; future research could use time diaries to increase the reliability of parental reports of superhero viewing. Finally, we should note that the parental mediation measure was not specific to superhero programs; instead it measured general mediation of all types of media. Accordingly, future research should examine how parental mediation specific to superhero programs influences gender play and activities in preschoolers.

Despite these limitations, this study provides the first evidence that viewing superhero programs in the media is related to greater adherence to gender stereotypes for boys in terms of play and activities, both in the short- and long-term. Additionally, exposure to such media was also associated with increased weapon play for both boys and girls. Conversely, prior levels of gender stereotyping predicted increased viewing of superhero programs for girls only. Importantly, these long-term effects were found even after controlling for initial levels of both constructs. In contrast to expectations, parental mediation either had no effect or in one case actually strengthened the associations. Superheroes have many positive qualities, such as saving, protecting, and defending those in peril; however, our research suggests that exposure to such programs during the preschool years may be a cause for concern; given the associations with heightened male-stereotyped play and weapon play over time. Because parental mediation does not negate such associations, or may even backfire, parents may best consider limiting media superhero exposure in preschool children.

Acknowledgments We would like to acknowledge the Women's Research Initiative at BYU for financially supporting this project. We would also like to thank all the student research assistants for their help throughout the project. 


\section{References}

Anderson, C. A., Benjamin, A. R., \& Bartholow, B. D. (1998). Does the gun pull the trigger? Automatic priming effects of weapon pictures and weapon names. Psychological Science, 9, 308-314. doi:10. 1111/1467-9280.00061.

Anderson, C. A., Berkowitz, L., Donnerstein, E., Huesmann, L. R., Johnson, J. D., Linz, D., et al. (2003). The influence of media violence on youth. Psychological Science in the Public Interest, 4 , 81-110. doi:10.1111/j.1529-1006.2003.pspi_1433.x.

Anderson, C. A., Gentile, D. A., \& Buckley, K. E. (2007). Violent video game effects on children and adolescents: Theory, research, and public policy. New York, NY US: Oxford University Press. doi:10. 1093/acprof:oso/9780195309836.001.0001.

Archer, J. (2004). Sex differences in aggression in real-world settings: A meta-analytic review. Review of General Psychology, 8, 291-322. doi:10.1037/1089-2680.8.4.291.

Ashby, M. S., \& Wittmaier, B. C. (1978). Attitude changes in children after exposure to stories about women in traditional or nontraditional occupations. Journal of Educational Psychology, 70, 945-949. doi: 10.1037/0022-0663.70.6.945.

Austin, E. W., Hust, S. J. T., \& Kistler, M. E. (2009). Powerful media tools: Arming parents with strategies to affect children's interactions with commercial interests. In T. J. Socha \& G. H. Stamp (Eds.), Parents and children communicating with society: Managing relationships outside of home (pp. 215-240). New York: Routledge.

Baker, K., \& Raney, A. A. (2007). Equally super?: Gender-role stereotyping of superheroes in children's animated programs. Mass Communication \& Society, 10, 25-41. doi:10.1080/15205430709337003.

Bandura, A., Ross, D., \& Ross, S. A. (1963). Imitation of film-mediated aggressive models. The Journal of Abnormal and Social Psychology, 66(1), 3-11. doi:10.1037/h0048687.

Bauer, K. L., \& Dettore, E. (1997). Superhero play: What's a teacher to do? Early Childhood Education Journal, 25, 17-21. doi:10.1023/ A: 1025677730004

Bendis, B. M., \& Dini, P. (2012). Ultimate Spider-Man [TV]. Glendale, CA: Marvel Animation Studios.

Bettencourt, B. A., \& Miller, N. (1996). Gender differences in aggression as a function of provocation: A meta-analysis. Psychological Bulletin, 119, 422-447. doi:10.1037//0033-2909.119.3.422.

Beuf, A. (1974). Doctor, lawyer, household drudge. Journal of Communication, 24, 142-145. doi:10.1111/j.1460-2466.1974. tb00380.x.

Blakemore, J. (2003). Children's beliefs about violating gender norms: Boys shouldn't look like girls, and girls shouldn't act like boys. Sex Roles, 48, 411-419. doi:10.1023/A:1023574427720.

Brand, J. (1996). Effects of gender identity, child development and televised counter-stereotyped messages about masculinity on male children's gender stereotypes. Dissertation Abstracts International Section A, 57, 1-196.

Brown, L. M., Lamb, S., \& Tappan, M. (2009). Packaging boyood: Saving our sons from superheroes, slackers, and other media stereotypes. New York: St. Martin's Press.

Bussey, K., \& Bandura, A. (1984). Influence of gender constancy and social power on sex-linked modeling. Journal of Personality and Social Psychology, 47, 1292-1302. doi:10.1037/0022-3514.47.6.1292.

Bussey, K., \& Bandura, A. (1992). Self-regulatory mechanisms governing gender development. Child Development, 63, 12361250. doi:10.1111/j.1467-8624.1992.tb01692.x

Bussey, K., \& Bandura, A. (1999). Social cognitive theory of gender development and differentiation. Psychological Review, 106, 676713. doi:10.1037/0033-295X.106.4.676.

Cantor, J., \& Wilson, B. (1984). Modifying fear responses to mass media in preschool and elementary school children. Journal of Broadcasting, 28, 431-443. doi:10.1080/08838158409386552.
Caufield, M. (2002, May). The influence of war play theme on cooperation and affective meaning in preschoolers' pretend play. Dissertation Abstracts International Section A, 62.

Collins, R. L. (2011). Content analysis of gender roles in media: Where are we now and where should we go? Sex Roles, 64, 290-298. doi: 10.1007/s11199-010-9929-5.

Corder-Bolz, C. R. (1980). Mediation: The role of significant others. Journal of Communication, 30, 106-118. doi:10.1111/j.14602466.1980.tb01997.x.

Costabile, A., Genta, M., Zucchini, E., Smith, P. K., \& Harker, R. (1992). Attitudes of parents toward war play in young children. Early Educaiton and Development, 3, 356-369. doi:10.1207/ s15566935eed0304 6.

Côté, S. M., Vaillancourt, T., Barker, E. D., Nagin, D., \& Tremblay, R. E. (2007). The joint development of physical and indirect aggression: Predictors of continuity and change during childhood. Developmental Psychopathology, 19, 37-55. doi:10.1017/ S0954579407070034.

Davies, M. (1997). Fake, fact, and fantasy: Children's interpretations of television reality. Hillsdale, NJ England: Lawrence Erlbaum Associates, Inc.

Eagly, A. H., \& Steffen, V. J. (1986). Gender and aggressive behavior: A meta-analytic review of the social psychological literature. Psychological Bulletin, 100, 309-330. doi:10.1037//0033-2909. 100.3.309.

Elias, C., \& Berk, L. (2002). Self-regulation in young children: Is there a role for sociodramatic play? Early Childhood Research Quarterly, 17, 216-238. doi:10.1016/S0885-2006(02)00146-1.

England, D. E., Descartes, L., \& Collier-Meek, M. A. (2011). Gender role portrayal and the Disney Princesses. Sex Roles, 64, 555-567. doi:10. 1007/s11199-011-9930-7.

Fehr, K. K., \& Russ, S. W. (2013). Aggression in pretend play and aggressive behavior in the classroom. Early Education and Development, 24, 332-345. doi:10.1080/10409289.2012.675549.

Feige, K., \& Black, S. (2013). Iron Man 3 [DVD] Burbank, CA: Marvel Studios.

Feige, K., \& Whedon, J. (2012). The Avengers [DVD] Burbank, CA: Marvel Studios.

Frueh, T., \& McGhee, P. E. (1975). Traditional sex role development and amount of time spent watching television. Developmental Psychology, 11, 109. doi:10.1037/h0076133.

Gentile, D. A., Lynch, P. J., Linder, J. R., \& Walsh, D. A. (2004). The effects of violent video game habits on adolescent hostility, aggressive behaviors, and school performance. Journal of Adolescence, 27, 5-22. doi:10.1016/j.adolescence.2003.10.002.

Golombok, S., \& Rust, J. (1993). The Pre-school activities inventory: A standardized assessment of gender role in children. Psychological Assessment, 5, 131-136. doi:10.1037/1040-3590.5.2.131.

Halim, M., Ruble, D. N., \& Tamis-LeMonda, C. S. (2013a). Four-yearolds' beliefs about how others regard males and females. British Journal of Developmental Psychology, 31, 128-135. doi:10.1111/j. 2044-835X.2012.02084.x.

Halim, M., Ruble, D., Tamis-LeMonda, C., \& Shrout, P. E. (2013b). Rigidity in gender-typed behaviors in early childhood: A longitudinal study of ethnic minority children. Child Development, 84, 1269 1284. doi:10.1111/cdev.12057.

Hawkins, R. P. (1977). The dimensional structure of children's perceptions of television reality. Communication Research, 4, 299-320. doi: $10.1177 / 009365027700400304$.

Hayes, A. F. (2013). An introduction to mediation, moderation, and conditional process analysis: A regression-based approach. New York: Guilford Press.

Hayes, A. F., \& Matthes, J. (2009). Computational procedures for probing interactions in OLS and logistic regression: SPSS and SAS implementations. Behavior Research Methods, 41, 924-936. 
Herrett-Skjellum, J., \& Allen, M. (1996). Television programming and sex stereotyping: A meta-analysis. In B. R. Burleson (Ed.), Communication yearbook (Vol. 19, pp. 157-185). Thousand Oaks, CA: Sage.

Hether, H. J., \& Murphy, S. T. (2010). Sex roles in health storylines on prime time television: A content analysis. Sex Roles, 62, 810-821. doi:10.1007/s11199-009-9654-0.

Hoffner, C. (1996). Children's wishful identification and parasocial interaction with favorite television characters. Journal of Broadcasting and Electronic Media, 40, 389-402. doi:10.1080/ 08838159609364360.

Hofstede, G. (2001). Culture's consequences: Comparing values, behaviors, institutions, and organizations across nations (2nd ed.). Thousand Oaks, CA: Sage.

Holland, P. (2003). We don't play with guns here: War, weapon and superhero play in the early years (Debating play). Maidenhead, England: Open University Press.

Hust, S. T. (2006). From sports heroes and jackasses to sex in the city: Boys' use of the media in construction of masculinities. Dissertation Abstracts International Section A, 67, 18.

Iger, B. (2006). Walt Disney Company annual meeting of shareholders 2006. Retrieved from http://media.disney.go.com/investorrelations/ presentations/060310 transcript.pdf

Javors, I. (2004). Hip-hop culture: Images of gender and gender roles. Annals of the American Psychotherapy Association, 7, 42.

Johnston, J., \& Ettema, J. (1982). Positive images: Breaking stereotypes with children's television. Beverly Hills, CA: Sage.

Lamb, M. E., Easterbrooks, M. A., \& Holden, G. W. (1980). Reinforcement and punishment among preschoolers: Characteristics, effects and correlates. Child Development, 51, 1230-1236.

List of American Superhero Films. (n.d.). In Wikipedia. Retrieved March 14, 2014, from http://en.wikipedia.org/wiki/List_of_American_ superhero_films.

Martin, J. F. (2007). Children's attitudes toward superheroes as a potential indicator of their moral understanding. Journal of Moral Education, $36,239-250$

Marvel's The Avengers. (2012). Retrieved from http://boxofficemojo. com $/$ movies $/$ ? id=avengers 11 .htm

Mayes, S. L., \& Valentine, K. B. (1979). Sex role stereotyping in Saturday morning cartoon shows. Journal of Broadcasting, 23, $41-50$

McCreary, D. R., \& Sasse, D. K. (2000). An exploration of the drive for muscularity in adolescent boys and girls. Journal of American College Health, 48, 297-304. doi:10.1080/07448480009596271.

Murnen, S. K., Smolak, L., Mills, J., \& Good, L. (2003). Thin, sexy women and strong, muscular men: Grade-school children's responses to objectified images of women and men. Sex Roles, 49, 427-437. doi: 10.1023/A:1025868320206.

Nam, K., Lee, G., \& Hwang, J. (2011). Gender stereotypes depicted by Western and Korean advertising models in Korean adolescent girls' magazines. Sex Roles, 64, 223-237. doi:10.1007/s11199010-9878-Z.

Nathanson, A. I. (2001). Mediation of children's television viewing: Working toward conceptual clarity and common understanding. In W. Gudykunst (Ed.), Communication yearbook (Vol. 25, pp. 115151). Mahwah, NJ: Lawrence Erlbaum.

Nathanson, A. I. (2004). Factual and evaluative approaches to modifying children's responses to violent television. Journal of Communication, 54, 321-336. doi:10.1093/joc/54.2.321.

Nathanson, A. I., \& Botta, R. A. (2003). Shaping the effects of television on adolescents' body image disturbance: The role of parental mediation. Communication Research, 30, 304-331. doi:10.1177/ 0093650203030003003

Nathanson, A. I., \& Cantor, J. (2000). Reducing the aggressionpromoting effect of violent cartoons by increasing children's fictional involvement with the victim: A study of active mediation. Journal of Broadcasting and Electronic Media, 44, 125-142. doi:10.1207/ s15506878jobem4401 9.

Nathanson, A. I., Wilson, B. J., McGee, J., \& Sebastian, M. (2002). Counteracting the effects of female stereotypes on television via active mediation. Journal of Communication, 52, 922-937. doi:10. 1111/j.1460-2466.2002.tb02581.x.

O'Bryant, S. L., \& Corder-Bolz, C. R. (1978). The effects of television on children's stereotyping of women's work roles. Journal of Vocational Behavior, 12, 233-244. doi:10.1016/ 0001-8791(78)90038-6.

Paek, H., Nelson, M. R., \& Vilela, A. M. (2011). Examination of genderrole portrayals in television advertising across seven countries. Sex Roles, 64, 192-207. doi:10.1007/s11199-010-9850-y.

Pecora, N. (1992). Superman/superboys/supermen: The comic book hero as socializing agent. In S. Craig (Ed.), Men, masculinity, and the media (pp. 61-77). Thousand Oaks, CA US: Sage Publications, Inc.

Peterson, J. B., \& Flanders, J. L. (2005). Play and the regulation of aggression. In R. E. Tremblay, W. W. Hartup, \& J. Archer (Eds.), Developmental origins of aggression (pp. 133-157). New York: Guilford Press.

Piaget, J. (1932). Play, dreams, and imitation in childhood. New York: Norton.

Popper, S. (2013). Rethinking superhero and weapon play. Maidenhead, England: Open University Press.

Prusank, D. T. (2007). Masculinities in teen magazines: The good, the bad, and the ugly. The Journal of Men's Studies, 15, 160-177. doi: 10.3149/jms.1502.160.

Register, S. (2010). Young Justice [TV]. Burbank, CA: Warner Bros Animation.

Register, S., \& Timm, B. (2011). Green Lantern [TV]. Burbank, CA: Warner Bros Animation.

Rosenthal, T. L., \& Zimmerman, B. J. (1978). Social learning and cognition. New York: Academic.

Ruble, D. N., Martin, C., \& Berenbaum, S. (2006). Gender development. In W. Damon, R. M. Lerner, \& N. Eisenberg (Eds.), Handbook of child psychology: Vol. 3. Social emotional, and personality development (6th ed., pp. 858-932). Hoboken: Wiley.

Rudy, R. M., Popova, L., \& Linz, D. G. (2010). The context of current content analysis of gender roles: An introduction to a special issue. Sex Roles, 62, 705-720. doi:10.1007/s11199-010-9807-1.

Rudy, R. M., Popova, L., \& Linz, D. G. (2011). Contributions to the content analysis of gender roles: An introduction to a special issue. Sex Roles, 64, 151-159. doi:10.1007/s11199-011-9937-0.

Russ, S. (2004). Play in child development and psychotherapy: Toward empirically supported practice. Mahwah, NJ: Erlbaum.

Sandnabba, N. K., \& Ahlberg C. (1999). Parents' attitudes and expectations about children's cross-gender behavior. Sex Roles 40, 249-263.

Seem, S. R., \& Clark, M. D. (2006). Healthy women, healthy men, and healthy adults: An evaluation of gender role stereotypes in the twenty-first century. Sex Roles, 55, 247-258. doi:10.1007/s11199006-9077-0.

Serbin, L. A., Powlishta, K. K., \& Gulko, J. (1993). The development of sex typing in middle childhood. Monographs of The Society for Research in Child Development, 58, v-74. doi:10.2307/1166118.

Signorielli, N., \& Lears, M. (1992). Children, television, and conceptions about chores: Attitudes and behaviors. Sex Roles, 27, 157-170. doi: 10.1007/BF00290015.

Slaby, R. G., \& Frey, K. S. (1975). Development of gender constancy and selective attention to same-sex models. Child Development, 46, 849-856. doi:10.2307/1128389.

Smith, P. K. (1994). The war play debate. In J. H. Goldstein (Ed.), Toys, play, and child development (pp. 67-84). Cambridge, UK: Cambridge University Press.

Smith, S. L., Pieper, K. M., Granados, A., \& Choueiti, M. (2010). Assessing gender-related portrayals in top-grossing G-rated films. Sex Roles, 62, 774-786. doi:10.1007/s11199-009-9736-z. 
Thompson, T. L., \& Zerbinos, E. (1997). Television cartoons: Do children notice it's a boy's world. Sex Roles, 37, 415-432. doi:10.1023/ A: 1025657508010

Underwood, M. K., Beron, K. J., \& Rosen, L. H. (2009). Continuity and change in social and physical aggression from middle childhood through early adolescence. Aggressive Behavior, 35, 357-375. doi: 10.1002/ab.20313.

Valkenburg, P. M. (2004). Children's responses to the screen. Mahwah, NJ: Erlbaum.

Wallis, C. (2011). Performing gender: A content analysis of gender display in music videos. Sex Roles, 64, 160-172. doi:10.1007/ s11199-010-9814-2.

Walsh, M. (2013, March 22). Kindergarten boy's toy gun gets him suspended from school - and his mom's fighting mad. New York Daily News. Retrieved from http://www.nydailynews.com/news/national/momfighting-suspension-son-6-toy-gun-school-article-1.1296226.
Watson, M. W., \& Peng, Y. (1992). The relation between toy gun play and children's aggressive behavior. Early Education and Development, 3, 370-389. doi:10.1207/s15566935eed0304 7.

Wegener-Spohring, G. (1994). War toys and aggressive play scenes. In J. H. Goldstein (Ed.), Toys, play, and child development (pp. 67-84). Cambridge, UK: Cambridge University Press.

Wilson, B. J., \& Cantor, J. (1987). Reducing children's fear reactions to mass media: Effects of visual exposure and verbal explanation. In M. M. McLaughlin (Ed.), Communication yearbook (Vol. 10, pp. 553-573). Newbury Park, CA: Sage.

Worldwide grosses (2014). Retrieved from http://boxofficemojo.com/ alltime/world/

Zosuls, K. M., Miller, C., Ruble, D. N., Martin, C., \& Fabes, R. A. (2011). Gender development research in sex roles: Historical trends and future directions. Sex Roles, 64, 826-842. doi:10.1007/s11199010-9902-3. 